\title{
An examination of the seductive details effect in terms of working memory capacity
}

\author{
CHRISTOPHER A. SANCHEZ and JENNIFER WILEY \\ University of Illinois, Chicago, Illinois
}

\begin{abstract}
Previous work on learning from text has demonstrated that although illustrated text can enhance comprehension, illustrations can also sometimes lead to poor learning outcomes when they are not relevant to understanding the text. This phenomenon is known as the seductive details effect. The first experiment was designed to test whether the ability to control one's attention, as measured by working memory span tasks, would influence the processing of a scientific text that contained seductive (irrelevant) images, conceptually relevant images, or no illustrations. Understanding was evaluated using both an essay response and an inference verification task. Results indicated that low working memory capacity readers are especially vulnerable to the seductive details effect. In the second experiment, this issue was explored further, using eye-tracking methodology to evaluate the reading patterns of individuals who differed in working memory capacity as they read the same seductively illustrated scientific text. Results indicated that low working memory individuals attend to seductive illustrations more often than not and, also, for a longer duration than do those individuals high in working memory capacity.
\end{abstract}

Within the past few decades, several theories have emerged in an attempt to account for the complex cognitive activity of text comprehension and learning from text (Goldman, 1997; Kintsch, 1988, 1998; Kintsch \& van Dijk, 1978). With ever more frequency, it appears that such theories not only must take into account the static characteristics of a text (i.e., structure, cues, and presence of illustrations), but also must account for individual differences between readers (e.g., in terms of cognitive ability, motivation, or prior knowledge). In the present line of research, we examined one potential interaction between text and learner characteristics-namely, the effects of working memory capacity (WMC) on learning from illustrated text.

\section{The Seductive Details Effect}

Previous work on learning from text has demonstrated that although illustrated text can enhance learning (Balluerka, 1995; Mayer, 1994, 1999; Mayer \& Gallini, 1990),

\footnotetext{
This article is based on a thesis submitted to the University of Illinois at Chicago in partial fulfillment of the requirements for the M.A. degree for the first author. The research was generously supported by Grant N000140110339 from the Office of Naval Research to the second author. Any opinions, findings, and conclusions or recommendations expressed in this material are those of the author(s) and do not necessarily reflect the views of this institution. We thank Andrew R. A. Conway and Susan R. Goldman for their insights on the overall project as members of the thesis committee. We also thank Ivan K. Ash for his thoughtful comments on this project and research assistants Sadia Ahmed, Artis Diggins, Hera Drandakis, Nadia Halim, Cara Jolly, and Mital Patel for their help in running experimental sessions. Correspondence concerning this article should be addressed to C. A. Sanchez, Department of Psychology, University of Illinois, 1007 W. Harrison St. (M/C 285), Chicago, IL 60607 (e-mail: csanch4@uic.edu).
}

illustrations can also sometimes lead to poor learning outcomes. Within the text-processing literature, there exists a phenomenon known as the seductive details effect (Garner, Brown, Sanders, \& Menke, 1992). The notion behind this seduction effect is that by adding additional, irrelevant information to a text, the comprehension of the text as a whole will be reduced (Harp \& Mayer, 1997). In Harp and Mayer's (1997) study, a group of college undergraduates were given a descriptive text that (1) did not contain any seductive information, (2) contained seductive text, (3) contained seductive illustrations, or (4) contained both seductive text and illustrations. It was found that in terms of both recall and problem-solving performance, individuals in conditions that contained any type of seductive information (textual, visual, or both) performed significantly worse than individuals in the base text condition. Furthermore, the detriment in reading performance was accompanied by higher levels of emotional interest in the seductive conditions (Harp \& Mayer, 1997). This reduction in performance and the enhancement of emotional interest has been replicated in several studies, using both scientific and narrative texts (Garner, Gillingham, \& White, 1989; Harp \& Mayer, 1998; Wade \& Adams, 1989).

\section{What Are Possible Explanations for the Seductive Details Effect?}

It has been argued that the main cause of the seductive details effect is the increase of emotional interest in the reader (Harp \& Mayer, 1997, 1998). On the one hand, seductive details are interesting, and piqued interest may increase motivation and learning. For example, interest has been shown to correlate well with deep learning from text (Schiefele, 1999). However, Kintsch (1980) made an 
important distinction between what he termed emotional and cognitive interest. Characteristics such as content, desire for knowledge, and style are features that promote cognitive interest in a given topic while one is reading (Kintsch, 1980). Information that is interesting in terms of the human condition (e.g., violence or sex), which is in itself emotionally arousing, represents emotional interest. It has been suggested that increased emotional interest can reduce learning if it causes the individual to become less cognitively interested in the subject matter (Wade, 1992). This was exactly the finding of Harp and Mayer's (1997) study.

In an attempt to explain this seduction effect in terms of possible mechanisms, Harp and Mayer (1998) hypothesized three potential causes for failures in comprehension due to the presence of irrelevant information: distraction, disruption, and diversion. Distraction attributes the reduction in comprehension to the reader's attention's being "seduced" away from relevant information toward emotionally interesting but irrelevant information (e.g., focusing on the irrelevant images, rather than on the text). The disruption hypothesis explains poor comprehension as being a result of breaks in the causal chain of events that is being constructed by the reader as he or she proceeds through the text. Seductive images prevent the reader from starting where he or she left off and, thus, lead to incomplete or incoherent representations of the text (Harp \& Mayer, 1998). Finally, the diversion hypothesis explains poor comprehension by the activation of incorrect schematic representations (encouraged by the seductive details) that lead to erroneous interpretations of the text.

Recent research has demonstrated that the diversion hypothesis does not likely represent the manner in which seductive details affect the learning process (at least with seductive images). Wiley (2003) demonstrated that presenting images before a text reduced the negative impact of seductive imagery, while still increasing levels of interest for readers of history texts. In a parallel study, Wright, Milroy, and Lickorish (1999) found that presenting animation before a text also reduced any detriment to performance, when compared with embedded animation within a text. If poor comprehension were simply due to the reader's being given an inappropriate schema, presenting images beforehand should lead to equally poor, if not worse, learning outcomes. Since improvements were actually seen in understanding when the seductive images were presented before the text, one of the two remaining explanations-distraction or disruption-is more likely to account for the poor comprehension of seductively illustrated text.

Both of the remaining explanations for the seduction effect involve some sort of interference that occurs as a result of the presence of seductive imagery and, thus, causes a breakdown in some part of the comprehension process. In the case of distraction, the interference is manifested in how one attends to relevant information (whether one does or does not). In terms of disruption, the interference from seductive details impacts the construction process needed to form a coherent model of the text. Either of these breakdowns could be the result of (or at least highly correlated with) individual differences in the ability to control attention within the working memory system. This coincides with previous speculations by Garner et al. (1992), who suggested that low-WMC individuals do not read in a very "strategic, conscious, or selective" way (p. 251).

\section{Working Memory and Controlled Attention}

The theoretical premise of WMC, originally proposed by Baddeley and Hitch (1974), has since been expanded and implicated in several complex cognitive processes. Most relevant for this study, measures of WMC have been related to both reading comprehension and the reading process (Daneman \& Carpenter, 1980; Just \& Carpenter, 1992; Turner \& Engle, 1989; Waters \& Caplan, 1996). It has also been suggested that differences in WMC may underlie the distinction between highly skilled and less skilled readers (Gernsbacher, Varner, \& Faust, 1990; Goldman, Hogaboam, Bell, \& Perfetti, 1980).

Original conceptualizations viewed WMC as a measure of the limited amount of information that one is able to maintain active or available to consciousness - essentially, a buffer system for the mind. Engle and colleagues have suggested an alternative to this limited-capacity viewpoint, known as the controlled attention perspective of working memory (Conway \& Engle, 1994). For purposes of clarity, WMC from the controlled attention perspective is the ability to control attention and deal with irrelevant information, and not simply the amount of information that can reside in working memory.

In simple terms, the underlying premise of the controlled attention viewpoint is that individual differences are not due to some limited amount of activation available to the working memory system but, rather, to an individual's ability to ignore irrelevant information (on the basis of a specific relevant goal) through the control of attention (Conway \& Engle, 1994; Kane, Bleckley, Conway, \& Engle, 2001). This conceptualization of WMC has been supported with several different paradigms, such as dichotic listening, variations of the Stroop task, and an antisaccade task (Conway \& Kane, 2001). In all these tasks, subjects with low WMC are more likely to make "slips" that violate the task goal that they were assigned (i.e., shadow the left ear, name the color, or do not look at the flash). High-WMC individuals have also been shown to be more resistant to proactive interference than are lowWMC individuals, provided there are no other, concurrent demands on their attention (e.g., no need to divide attention; Kane \& Engle, 2000; Rosen \& Engle, 1997).

Taken together, these results suggest that individuals who possess lower WMC are generally less able to utilize executive control to ignore irrelevant or interfering information and maintain focus on a specific goal, whereas the exact opposite is true for high-WMC individuals. With regard to text processing, the ability to control one's attention may be critical for the successful comprehension of text, especially when the text contains irrelevant information. 


\section{Individual Differences in Learning From Illustrated Text}

It is reasonable to believe that individuals deal with interest and demands on their attention in different ways and that this demand might manifest itself in different ways while they are reading and trying to understand text. The controlled attention view predicts that individuals with low WMC may not possess the executive ability to deal with an increase in non-goal-related interest in an appropriate manner and that this inability might affect how well they can learn from a text with seductive illustrations.

For example, it is possible that low-WMC individuals would be unable to maintain their original goal of comprehension in the face of irrelevant, interesting information. Another, less appropriate goal could supplant the original learning goal (e.g., focusing on an image, rather than on the text), and thus, comprehension of the text would naturally suffer. Similarly, in the presence of highly emotional, interesting information, it is possible that individuals with low WMC cannot help but focus on this irrelevant information.

In addition, the controlled attention view predicts that high-WMC individuals should be better able to deal with the interference provided by seductive details while processing a text. Thus, one would expect that high-WMC individuals would show little to no seduction effect, due to their increased ability to control their attention.

In order to investigate this potential interaction between controlled attention and the seductive details effect, two experiments were conducted. The first experiment was designed to examine whether or not WMC would affect the comprehension of illustrated text overall and, assuming that effects due to WMC were found, under what circumstances this effect would be most pronounced. The second experiment provided a direct follow-up to the results of the first experiment by using eye-tracking methodology to examine any potential differences between low- and high-WMC readers as they read a seductively illustrated text.

In the first experiment, individuals who differed in WMC were assessed in their overall comprehension of an expository text that either was illustrated with conceptual or seductive images or was not illustrated. The subjects were prescreened for their WMC in a separate session before this experiment, as will be described below. The purpose of this experiment was to examine whether or not WMC would have an influence on the comprehension of illustrated expository text and whether the influence of WMC would differ on the basis of the type of illustration (i.e., conceptual illustrations vs. seductive illustrations). On the basis of prior research, it was expected that WMC would be related to comprehension of expository text in general but, also, that the influence of WMC would be more pronounced in the seductive illustrations condition than in the other conditions, given that this condition required the reader to deal with irrelevant, interfering information. As a whole, this first experiment addressed whether or not individual differences in WMC would predict the seductive details effect and also, in a larger sense, to what extent WMC would affect the processing of illustrated text.

\section{EXPERIMENT 1}

\section{Method}

\section{Subject Prescreening}

Seven hundred sixty-four undergraduates at the University of Illinois at Chicago, who participated in the introductory psychology subject pool, were prescreened for their performance on working memory span tasks. The subjects were run in two tests of WMC as adapted by Kane et al. (2004). These two tests were operation span (OSPAN), originally developed by Turner and Engle (1989), and reading span (RSPAN), originally developed by Daneman and Carpenter (1980).

\section{Operation Span}

The OSPAN task involved presenting several series of displays to the subject on a computer screen. The number of displays that compose a series varied between two and five, and each display consisted of a single mathematical equation and an answer, and after the equation, an unrelated word in capitals was also displayed. Each series length was presented three times and resulted in a net total of 12 series. The subjects were required to evaluate the correctness of the given equation and to answer by responding either yes or no [e.g., " $(5+3) / 2=4$; yes; DOG" or " $(5+3) / 2=2$; no; CLASS"]. Following the subjects' yes/no response, they were then required to immediately say, and remember, the word that followed the equation. After the last display in a series was completed (as indicated by three question marks in the middle of the screen; e.g., ???), the subjects were given a blank response sheet and were asked to write down all the words that they were able to remember for that series, in the same order as that in which they had appeared. The subjects were not allowed to return to any of their previous answers or to modify them in any way. They were allowed as much time as necessary to complete their response to a given series. Also, they were evaluated on the correctness of their yes/no responses to the equation. Any subjects who made more than eight errors on the OSPAN task were not retained for any later analysis.

Each subject's score was determined by calculating a percentage of the total number of words correctly recalled in serial order for each individual series and then computing an overall proportion correct, on the basis of the average percentage correct for all of the 12 series. Responses were not counted as correct if the words were recalled in the incorrect order or if a word was skipped or omitted. Thus, a response was counted as correct only if the word was in the correct serial order and the word itself was correctly recalled.

\section{Reading Span}

WMC was also assessed using the RSPAN task. This RSPAN task was virtually identical to the OSPAN task, except that instead of equations, the subjects were required to read a sentence aloud, evaluate whether or not the sentence made sense, and then say and remember an unrelated, capitalized letter that was presented after the sentence (e.g., "People in our town are more giving and cheerful at Christmas time.; yes; Q" or "Andy was stopped by the policeman because he crossed the yellow heaven.; no; D"). Sentences consisted of between 12 and 14 words, and the number of sentences in a trial series varied between two and five. Each series length was presented three times and resulted in a net total of 12 series. After the appropriate number of sentences had been displayed in a trial series, the subjects were then prompted with three question marks (???) and were asked to recall the unrelated letters that had been presented after the sentences in that given series. The subjects were asked to recall these letters in the order in which they had been presented. The subjects were also not permitted to modify their previous responses. Just as in the OSPAN task, the subjects were evaluated on the correctness of their responses as to whether or not the sentence made sense. Any subject who made over eight errors for this yes/no judgment in the RSPAN task was excluded from any subsequent analysis. 
As for the OSPAN task, a composite score was computed for the subjects after they had completed all of the series. They were assigned a percentage correct for each series, and then an overall proportion correct was computed by averaging the percentage correct for all of the 12 series. The subjects were not given credit for the letter if either the letter was incorrect or if the letter was recalled in the incorrect serial order position.

\section{Prescreening Procedure}

All the subjects were required to complete both the OSPAN task and the RSPAN task. The order of presentation of these tasks was counterbalanced across the range of subjects. The subjects were given up to $30 \mathrm{~min}$ to complete both tasks. These tasks were presented on IBM-compatible PCs, running E-Prime software. The subjects were also given two blank answer sheets to record their responses for each task. A WMC composite score was computed by averaging the proportion of correct scores for the OSPAN and RSPAN tasks.

\section{Prescreening Population Statistics}

It was found that the two measures of WMC (OSPAN and RSPAN) were highly correlated with each other $(r=.65, p<.001)$. This correlation demonstrates reliability of measures in this administration and also demonstrates that it is very likely that these two tasks are indeed measuring the same theoretical construct-namely, WMC. On the basis of overall population statistics, the subjects were designated as either low or high in WMC. Those subjects whose WMC composite score was in the upper third of the overall distribution (WMC composite scores $>$.71) were identified as high in WMC, whereas those whose scores were in the lower third of the distribution (WMC composite scores $<.60$ ) were considered to be low in WMC.

\section{Design}

A 2 (WMC) $\times 3$ (illustration condition) between-groups design was used to explore the potential interaction between individual differences in cognitive ability and reading performance for illustrated texts. Thus, both individuals high and those low in WMC read an identical expository text about ice ages, which was nonillustrated, illustrated with conceptually relevant illustrations, or illustrated with seductive illustrations.

\section{Subjects}

Subjects who had successfully completed prescreening were solicited for participation. Thus, 36 high-WMC and 36 low-WMC individuals were recruited for this main experiment. The subjects $(N=72)$ were all undergraduates at the University of Illinois at Chicago and were native English speakers. They were compensated with course credit in an introductory psychology course at the university.

Any subjects who either failed to successfully complete any portion of this experiment or were evaluated as high in knowledge prior to reading the text were not retained for the final analyses. A subject was designated high in prior knowledge if he or she successfully mentioned any of the causes of ice ages that were contained within the text in a prereading essay. This stringent criterion ensured that all the subjects were truly low in prior knowledge, and it was hoped that this might reduce any potential confound of existing knowledge on performance. All the subjects were randomly assigned to condition. As a result, there were 12 high-WMC and 12 low-WMC individuals in each of the three conditions.

\section{Materials}

The subjects read an expository text on the topic of what causes ice ages. This text was presented in Web page format and was subdivided into 13 discrete pages (each of which had a specific topic subheading). The subjects navigated between each of these pages, using links embedded at the bottom of each of the pages. These links allowed the subjects to advance to either the immediately succeeding or preceding page. Thus, the subjects were not allowed to advance either forward or backward in the text by more than 1 page at any given time.

The text was approximately 2,700 words long and was nonillustrated, illustrated with 12 conceptual images, or illustrated with 12 seductive images. These images were selected from several online sources, such as the United States Geological Survey and the Public Broadcasting Service (PBS), all of which dealt with the topic of ice ages. All the illustrations were normed for their emotional and conceptual interest in a rating study, presented in Appendix A. A sample of the nonillustrated text used in this experiment is available in Appendix B. Also, a sample of each type of illustration is included in Appendix C. The subjects read the Web page on IBM-compatible PCs, in either Netscape Communicator 4.7 or Microsoft Internet Explorer 6.0. All browser toolbars were unavailable to the subjects during the experiment.

Prior to reading the text, all the subjects completed a paper-andpencil prior knowledge evaluation. The subjects' prior knowledge and educational experience was assessed using four self-report questions that evaluated prior schooling and familiarity with the topic and also by asking the subjects to write a preliminary argument about the causes of ice ages, even if they knew very little about the causes of ice ages. The four self-report questions asked the subjects to rate, on a scale from 1 to 7 (1 being nothing and 7 being very much), their knowledge of (1) the causes of ice ages, (2) geology, (3) astronomy, and (4) global weather systems (meteorology).

After the subjects had finished reading the text, they were then asked to "Write an argument on the topic "what causes Ice Ages to occur?" This argumentative essay was evaluated in terms of the total number of correct causal factors recalled. The number of correct causal factors was assessed on the basis of a predetermined set of 15 that had been identified a priori in a causal model. These 15 ideas are available in Appendix D. The subjects were also asked to complete an inference verification task (IVT) that was presented on the computer. The IVT consisted of 25 statements that represented potential inferences (both correct and incorrect) that could be drawn from the text. Each of these statements was presented individually, and the subjects were instructed to evaluate the correctness of each of the statements by responding either true or false as quickly as possible (e.g., the total amount of $\mathrm{CO}_{2}$ in the atmosphere is stable and does not change; a correct answer would be false). For every correct and incorrect inference appropriately identified, the subjects received a single point. An overall score was computed for the IVT task, and higher levels of performance indicated a heightened ability to identify both correct and incorrect inferences.

\section{Procedure}

The subjects completed an informed consent form and the prior knowledge questionnaire. They were allowed $10 \mathrm{~min}$ to complete this task. After the questionnaire, the subjects were randomly assigned to an image condition, were directed to the main Web site, and were given $20 \mathrm{~min}$ to read the entire Web site. They were explicitly instructed that their goal while reading the text was "to develop an argument to answer the question 'What causes Ice Ages?" The subjects were instructed to read every page and were also given instructions on how to navigate between pages, using the embedded links. The subjects were allowed to read and reread at their own pace.

After the $20 \mathrm{~min}$ had passed, the subjects were given a blank response sheet and were asked to write an argumentative essay on what causes ice ages. Responses were required to be at least a page in length. While the subjects completed this task, the Web site was unavailable to them. They were allowed up to $20 \mathrm{~min}$ to complete writing their essay response. After they had finished writing their essay, they were then asked to complete the IVT. After completing the IVT, the subjects were debriefed and dismissed. The entire experimental session took no longer than $1 \mathrm{~h}$. 


\section{Results \\ Background Knowledge Variables}

Across all conditions, a $2(\mathrm{WMC}) \times 3$ (illustration condition) between-groups ANOVA showed that, on the basis of all four self-report background knowledge questions, there was no main effect of WMC $[F(1,66)=1.67$, $M S_{\mathrm{e}}=12.68, p>.05 ; \eta^{2}=.03$ ] or illustration condition $(F<1)$ and no interaction between WMC and illustration condition $(F<1)$. High-WMC individuals $(M=11.58$, $S D=3.54)$ and low-WMC individuals $(M=10.50, S D=$ $3.51)$ had similar knowledge levels, which was also consistent across the nonillustrated $(M=11.63, S D=4.23)$, conceptually illustrated $(M=10.29, S D=3.29)$, and seductively illustrated $(M=11.21, S D=3.00)$ conditions. This result demonstrates that knowledge level across groups was well matched.

\section{Essay Responses}

To test for overall effects of WMC and illustration condition on performance, a $2 \times 3$ between-groups ANOVA was conducted on the number of correct causes contained in each essay response. Descriptive statistics by image condition are presented in Figure 1. The results indicated that there was no main effect of either WMC $[F(1,66)=$ $\left.1.44, M S_{\mathrm{e}}=1.39, p>.05 ; \eta^{2}=.02\right]$ or illustration condition $(F<1)$. It appeared that neither WMC nor the content of the illustrations alone significantly impacted comprehension. However, there was a significant interaction between WMC and illustration condition $[F(1,66)=3.23$, $\left.M S_{\mathrm{e}}=1.39, p<.05 ; \eta^{2}=.09\right]$.

Planned comparisons indicated that low-WMC individuals in the nonillustrated and conceptual illustration conditions recalled similar amounts of information $(F<1)$. However, the presence of seductive images $(M=$ $.25, S D=.45)$ led to the recall of significantly fewer correct causes than in the nonillustrated condition $(M=1.17$, $S D=1.34)\left[F(1,22)=5.06, M S_{\mathrm{e}}=1.00, p<.05 ; \eta^{2}=\right.$ .19] and also marginally fewer than in the conceptually illustrated condition $(M=.75, S D=.75)[F(1,22)=3.88$, $M S_{\mathrm{e}}=0.39, p<.06 ; \eta^{2}=.15$ ] for low-WMC individuals. These results indicate that there was a seductive details effect for individuals low in WMC. Also interesting to note is the lack of a facilitative effect of conceptual illustrations above the level of the nonillustrated text.

For high-WMC individuals, planned comparisons indicated that the amount of correct causes recalled by the subjects in the nonillustrated condition $(M=1.00, S D=$ 1.28) was similar to the amounts recalled by the subjects in both the conceptually illustrated condition $(M=.58$, $S D=.67)$ and the seductive condition $(M=1.58, S D=$ 1.93) $(F \mathrm{~s}<1)$. Thus, there was no evidence of seduction within the high-WMC group with respect to the nonillustrated condition. Surprisingly, within the high-WMC group, it also appeared that the presence of seductive illustrations, as opposed to conceptual illustrations, seemed to increase performance $\left[F(1,22)=2.88, M S_{\mathrm{e}}=2.08\right.$, $\left.p<.10 ; \eta^{2}=.12\right]$. The presence of seductive illustrations thus tended to lead to the highest level of performance for

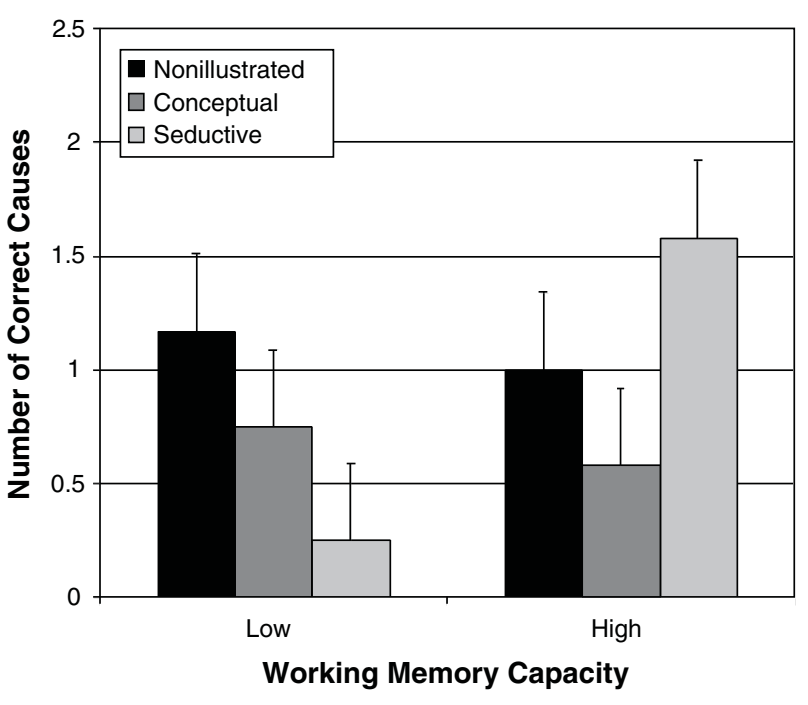

Figure 1. Number of correct causes included in essays by working memory capacity and illustration condition for Experiment 1 (error bars represent standard errors of the means).

those high in WMC, especially when compared with performance in the conceptual condition, although this effect was not statistically reliable.

The overall interaction of WMC and comprehension was also evident between WMC groups, since high-WMC individuals recalled significantly more correct causes than did low-WMC individuals in the seductive condition $\left[F(1,22)=5.44, M S_{\mathrm{e}}=1.96, p<.05 ; \eta^{2}=.20\right]$, whereas there was no difference between WMC groups in the nonillustrated or conceptual conditions $\left(F_{\mathrm{S}}<1\right)$.

\section{Inference Verification Task}

On this measure, a $2 \times 3$ between-groups ANOVA identified a significant main effect of WMC $[F(1,66)=$ $\left.10.75, M S_{\mathrm{e}}=4.50, p<.01 ; \eta^{2}=.14\right]$. Those higher in WMC $(M=15.28, S D=2.42)$ were better able to identify correct and incorrect inferences than were those lower in WMC $(M=13.64, S D=2.14)$. The main effect of illustration condition was not significant $[F(1,66)=2.01$, $\left.M S_{\mathrm{e}}=4.50, p>.05 ; \eta^{2}=.06\right]$. Mean performance by WMC and illustration condition is presented in Figure 2.

As is evident in Figure 2, there was a significant interaction between WMC and illustration condition $[F(1,66)=$ 5.64, $\left.M S_{\mathrm{e}}=4.50, p<.01 ; \eta^{2}=.15\right]$. For low-WMC individuals, planned comparisons indicated that the subjects performed similarly in the nonillustrated $(M=14.83$, $S D=2.12)$ and conceptually illustrated $(M=14.00$, $S D=1.95)$ conditions $(F<1)$. However, including seductive illustrations $(M=12.08, S D=1.38)$ led to performance that was significantly worse than that in both the nonillustrated $\left[F(1,22)=14.14, M S_{\mathrm{e}}=3.21, p<\right.$ $\left..01 ; \eta^{2}=.39\right]$ and the conceptually illustrated $[F(1,22)=$ $\left.7.71, M S_{\mathrm{e}}=2.86, p<.01 ; \eta^{2}=.26\right]$ conditions. Again, as was evident in the essay analyses, there was an obvious detriment in performance for low-WMC individuals when 


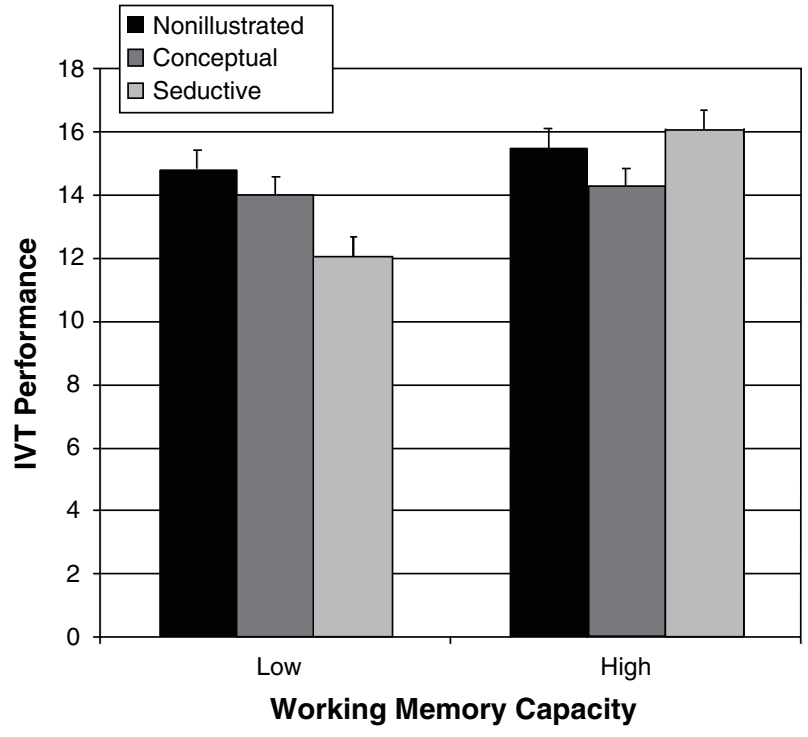

Figure 2. Inference verification task (IVT) performance by working memory capacity and illustration condition for Experiment 1 (error bars represent standard errors of the means).

a text was illustrated with seductive illustrations, versus the other two conditions. Similarly, there was no learning benefit produced by illustrating the text with conceptually relevant diagrams.

In contrast, for those high in WMC, there was no difference between the nonillustrated text condition $(M=$ $15.50, S D=2.20)$ and either the conceptually illustrated condition $(M=14.25, S D=2.70)[F(1,22)=1.55$, $\left.M S_{\mathrm{e}}=6.06, p>.05 ; \eta^{2}=.07\right]$ or the seductively illustrated condition $(M=16.08, S D=2.15)(F<1)$. Again, there was no evidence for seduction among those high in WMC. In addition, as also was suggested in the essay analyses, seductive illustrations led to marginally better performance than the conceptually illustrated condition $\left[F(1,22)=3.38, M S_{\mathrm{e}}=5.96, p<.08 ; \eta^{2}=.13\right]$. Thus, seductive illustrations did not negatively impact performance on the IVT and, in fact, tended to lead to the best performance of the three conditions.

The overall interaction of WMC and comprehension was likewise evident when a comparison was made between WMC groups, since high-WMC individuals performed significantly better in the seductive condition than did low-WMC individuals $\left[F(1,22)=29.40, M S_{\mathrm{e}}=\right.$ $\left.3.27, p<.01 ; \eta^{2}=.57\right]$, whereas there was no difference between WMC groups in either the nonillustrated or the conceptual condition $\left(F_{\mathrm{S}}<1\right)$.

\section{Discussion}

The results of this experiment suggest that a reader's WMC does indeed influence the comprehension of illustrated expository text when a text contains irrelevant information. Specifically, there appeared to be little divergence between the learning of the WMC groups in the nonillustrated and the conceptually illustrated conditions; however, there was clear evidence of a seduction effect only for the low-WMC group when the text contained irrelevant illustrations. Consistent with the predictions of the controlled attention view of working memory, low-WMC individuals were less able to deal with distracting information in irrelevant illustrations. One explanation of this finding is that the presence of appealing but ultimately irrelevant information caused the low-WMC readers to focus less on the relevant conceptual information contained within the text. Two measures of understanding-a causal analysis of student essays and performance on an inference test-were used to assess the situation model that readers had developed. The results of both measures supported the conclusion that low-WMC individuals developed a poorer understanding of the text in the irrelevant illustration condition.

The lack of a consistent overall effect for WMC on comprehension was somewhat unexpected. In our experiment, an overall advantage for high-WMC individuals was found with only one of the learning measures (the inference verification task), but not with the essay analysis. This is somewhat surprising, since there is a great deal of research that suggests that WMC is important for text comprehension in general (Daneman \& Carpenter, 1980; Just \& Carpenter, 1992; Turner \& Engle, 1989; Waters \& Caplan, 1996).

It is possible that the processing and integration demands of the IVT may depend more heavily on WMC. The IVT task is somewhat analogous to the tasks used to evaluate WMC and is more similar to tasks that have been used to evaluate learning in other studies that have shown working memory effects; hence, the effect observed here. However, recent research has suggested an attenuated relationship between WMC and construction of the situation model, which might explain the lack of a general WMC effect on this essay task (Radvansky \& Copeland, 2004). Thus, the process of writing an essay might simply be less sensitive to differences in WMC, although it has been shown to correlate with an individual's ability to hold and simultaneously process information in prior research (Benton, Kraft, Glover, \& Plake, 1984).

A second unexpected result was that for high-WMC individuals, seductive illustrations seemed to have the opposite effect from what has been previously hypothesized in the seductive details literature. Although this effect was not statistically reliable (as evidenced by marginal results in both the essay and the IVT responses), the results seem to suggest that this irrelevant information might help high-WMC individuals learn. Further research would be necessary to provide a concrete explanation of this effect, and we will not speculate upon it here.

Finally, in both the low- and the high-WMC groups, conceptual illustrations failed to provide any kind of positive learning benefit over plain text, despite their identification as relevant to the text (Appendix A). This finding is surprising, since several studies have demonstrated that conceptual images reliably facilitate the learning process (Mayer \& Gallini, 1990) through a speculated offloading of WMC resources (Bauer \& Johnson-Laird, 1993). The 
illustrations used in this experiment were specifically chosen to be redundant with the text, so that the plain text condition would provide a fair baseline comparison for the illustrated condition. It may be that conceptual illustrations that are not redundant with the text or that add some specific visual information that is not conveyed well by text alone are more likely to produce learning benefits over a plain text condition (Hegarty, Kriz, \& Cate, 2003; Larkin \& Simon, 1987).

In conclusion, this experiment has shown that when texts are illustrated with interesting but irrelevant images, WMC plays a significant role in comprehension. This finding is evidenced by the need to deal with distracting information in the irrelevant image condition and is consistent with a controlled attention perspective of WMC, rather than with a limited-capacity view (Kane et al., 2001). The fact that this detriment for low-WMC individuals occurred only in the presence of irrelevant information suggests that the amount that one can hold in an active state is not the key predictor of comprehension in such a situation (especially considering that there was no difference between groups in the remaining two conditions). Rather, the interpretation of WMC as the ability to successfully control one's attention in order to focus on relevant information and ignore the irrelevant appears to be the best explanation of these data.

To provide additional evidence for a controlled attention explanation of the seductive details effect, a second experiment was conducted using eye-tracking methodology. In the hopes of uncovering possible differences in reading patterns between groups, eye movements were recorded while subjects who were either low or high in WMC read the same seductively illustrated text as that used in the first experiment.

\section{EXPERIMENT 2}

Eye movement patterns have been examined in previous research on how readers process conceptual diagrams and graphs (Carpenter \& Shah, 1998; Hegarty, 1992; Hegarty \& Just, 1993) and have been used to identify the processes that better learners use. The same methodology was employed here, with the goal of providing similar insight into the seductive details effect and its relationship to individual differences in WMC. In accord with the results of Experiment 1, it was expected that low-WMC individuals would be more susceptible to the seduction effect than would high-WMC individuals. However, the question remains open as to what this seduction might look like and whether the pattern would be consistent only with the controlled attention perspective.

If one were to take a traditional capacity viewpoint of WMC, one might expect that there would be longer overall viewing times for both the text and the illustrations for low-WMC individuals than for high-WMC individuals. Due to their limited capacity, low-WMC individuals might take longer to process and integrate information into their representations simply because their cognitive system is taxed by having to do so much at a single time.
High-WMC individuals, on the other hand, are not so limited in their processing resources and should, in fact, be faster overall, a finding corroborated by prior research (Kaakinen, Hyönä, \& Keenan, 2003).

However, if one were to take a controlled attention viewpoint, overall differences in reading time might not be expected. Contrary to the capacity viewpoint, the controlled attention perspective predicts that differences should arise between groups specifically in the way in which the individuals deal with irrelevant information. Thus, one would expect high-WMC individuals to attend to seductive illustrations to a lesser degree than do lowWMC individuals. In plain words, high-WMC individuals should look at these illustrations less often-in essence, ignoring these irrelevant pieces of information. A capacity viewpoint cannot accommodate this lower viewing rate, since it attributes differences to processing overload, and not to the overt ignoring of irrelevant information.

To test these competing views, reading patterns of high- and low-WMC readers were examined as they read the seductively illustrated text used in Experiment 1 . Several measures of the subjects' reading behavior were computed, including overall reading time and number of fixations, regressions within the text while reading, overall time on illustrations and number of fixations, and finally, the overall number of illustrations viewed.

\section{Method}

\section{Design}

A two-way, between-groups design was used to further explore the seductive details effect. High- and low-WMC subjects were asked to read the text in the seductively illustrated condition while their eye movements were tracked.

\section{Subjects}

Subjects who had successfully completed prescreening and had not participated in Experiment 1 were solicited for participation. Five high-WMC and 5 low-WMC individuals chosen on the basis of the same criteria as those in Experiment 1 were recruited for this second experiment. The subjects were all undergraduates at the University of Illinois at Chicago and were native English speakers. The subjects were compensated with course credit in an introductory psychology course at the university.

As in Experiment 1, all the subjects were low in prior knowledge and successfully completed all portions of the subsequent experiment.

\section{Materials}

All the subjects read the same text as that in the seductive condition in the first experiment.

\section{Apparatus}

The subjects' eye movements while reading the text were recorded using an Eyelink II head-mounted eyetracker, manufactured by SR Research Ltd. (Toronto), which has 15 min of arc and a spatial accuracy of approximately $0.5^{\circ}$. Eye movements were measured via infrared video and were sampled at a rate of $250 \mathrm{~Hz}$. The subjects' viewing was binocular, and eye movements were capable of being recorded from either eye; however, for all sessions, eye movements were recorded from only one eye, either the right or left, whichever was more accurate on the basis of the calibration protocol for the eye-tracking apparatus. Head position and any subsequent head movement with respect to the computer screen were compensated for online, using information from a camera located in the head- 
band of the eye-tracking apparatus that computed relative location to LEDs placed at each of the four corners of the computer screen. Compensation for movement exceeded $1^{\circ}$ over the acceptable range of head motion. The eye-tracking system was interfaced with an IBM-compatible computer, which recorded all the eye movement data. The Web site was presented on an additional IBM-compatible PC, using Microsoft Internet Explorer 6.0. The subjects advanced through the Web site by using a mouse, just as in Experiment 1 .

\section{Procedure}

The procedure for this second experiment was identical to that in Experiment 1, save that prior to reading, the subjects were first briefed and then calibrated on the eye-tracking apparatus. After the subjects had finished reading the Web site, the eye-tracking apparatus was then removed for the remainder of the experiment. All other aspects of the procedure were identical to those in Experiment 1.

\section{Results and Discussion \\ Essay and IVT Analyses}

The results indicated that, as in Experiment 1, there was a seduction effect for low-WMC individuals in terms of their essay responses. Low-WMC individuals $(M=.60$, $S D=.55)$ recalled significantly fewer correct causes in their essays than high-WMC individuals $(M=2.00, S D=$ 1.22), as was evidenced by an independent samples $t$ test $\left[t(8)=2.33, p<.05 ; \eta^{2}=.41\right]$. However, there was no reliable difference in terms of performance on the IVT $\left[t(8)=0.38, p>.05 ; \eta^{2}=.02\right]$. Although the average performances for the high- $(M=14.40, S D=2.07)$ and low- $(M=13.80, S D=2.86)$ WMC groups on the IVT were within the ranges for the same groups in Experiment 1 , this difference was not significant. Both essay and IVT results are presented in Table 1, as well as the descriptive statistics for all the measures listed below.

\section{Eye-Tracking Analyses}

Overall reading time and number of fixations. In terms of overall reading time and number of fixations for the Web site, there was no reliable difference between high- and low-WMC individuals on either of these measures. High- $(M=10.48 \mathrm{~min}, S D=.90)$ and low- $(M=$ $10.11 \mathrm{~min}, S D=.61) \mathrm{WMC}$ individuals spent a similar amount of time reading all the information on the Web site $\left[t(8)=0.77, p>.05 ; \eta^{2}=.07\right]$, and high-WMC individu- als $(M=2,503.80, S D=308.16)$ had approximately the same number of fixations as did low-WMC individuals $(M=2,288, S D=193.66)\left[t(8)=-1.33, p>.05 ; \eta^{2}=\right.$ .18].

Regressions within text. The number of local and distant regressions within the text was also examined for high- and low-WMC individuals. Local regression was considered to be any backward fixation within the same line of text, whereas distant regression was operationalized as any backward fixation greater than one line of text. Between groups, there was no difference in the amount of local regressions within the text $[t(8)=0.37, p>.05$; $\left.\eta^{2}=.02\right]$. High-WMC individuals engaged in this local rereading as frequently as low-WMC individuals. However, high-WMC individuals had a significantly higher number of distant regressions within the text than did lowWMC individuals $\left[t(8)=2.45, p<.05 ; \eta^{2}=.43\right]$. These distant regressions can be seen as an attempt to better integrate information into a cohesive whole across the body of the text, as has been suggested in previous eye-tracking studies (Wiley, Mason, \& Myers, 2001). Thus, high-WMC individuals seem to be engaging in this integration process more often than low-WMC individuals, which likely impacts the nature of their understanding.

Illustration viewing time and rate of viewing. When the amount of overall time spent on the seductive illustrations was specifically looked at, it was found that high-WMC individuals spent less time viewing the illustrations than did the low-WMC group overall $[t(8)=2.73, p<.03$; $\left.\eta^{2}=.48\right]$.

Despite the overall difference in illustration viewing time, not all the subjects viewed all 12 illustrations. In fact, high-WMC individuals viewed significantly fewer of the 12 presented illustrations than did low-WMC individuals $\left[t(8)=2.63, p<.03 ; \eta^{2}=.46\right]$. Accounting for this difference in viewing rate, we then calculated the average time per illustration viewed. The results indicated that there was no difference between groups in terms of average time per illustration viewed $[t(8)=1.73, p>.05$; $\left.\eta^{2}=.27\right]$.

Reading time on text alone. When reading time on the text alone was considered (i.e., not including time on

Table 1

Learning Measures, Viewing Time Measures, and Regressions for Experiment 2

\begin{tabular}{|c|c|c|c|c|c|}
\hline & \multicolumn{2}{|c|}{ Low WMC } & \multicolumn{2}{|c|}{ High WMC } & \multirow[b]{2}{*}{$t$ Value } \\
\hline & $M$ & $S D$ & $M$ & $S D$ & \\
\hline \multicolumn{6}{|l|}{ Learning measures } \\
\hline Total causes in essay & 0.60 & 0.55 & 2.00 & 1.22 & $2.33^{*}$ \\
\hline Inference verification task & 13.80 & 2.86 & 14.40 & 2.07 & 0.38 \\
\hline \multicolumn{6}{|l|}{ Viewing time measures } \\
\hline Overall reading time $(\mathrm{min})$ & 10.11 & 0.61 & 10.48 & 0.90 & 0.77 \\
\hline Reading time text alone (min) & 9.97 & 0.60 & 10.41 & 0.88 & 0.93 \\
\hline Overall illustration viewing time (sec) & 8.19 & 1.81 & 4.27 & 2.65 & $2.73^{*}$ \\
\hline Average illustration viewing time (sec) & 0.95 & 0.27 & 0.63 & 0.30 & 1.73 \\
\hline \multicolumn{6}{|l|}{ Regressions within text (frequency) } \\
\hline Local regressions & 451.40 & 118.46 & 487.60 & 184.18 & 0.37 \\
\hline Distant regressions & 171.40 & 24.75 & 235.20 & 52.69 & $2.45^{*}$ \\
\hline Average number of illustrations viewed & 8.80 & 1.30 & 6.60 & 1.34 & $2.63^{*}$ \\
\hline
\end{tabular}

Note-WMC, working memory capacity. * Significant $t$ values. 
illustrations), no differences were found $[t(8)=0.93, p>$ $\left..05 ; \eta^{2}=.10\right]$. Thus, it appears that the amount of time spent processing the textual information was similar in both the low- and the high-WMC groups, and one group was not devoting significantly more time than the other to understanding the text base.

These results suggest that high-WMC individuals are not as susceptible to the seductive details effect, because they are better able to ignore the irrelevant illustrations and focus on the text. Thus, the chance of being "seduced" is much lower for high-WMC individuals. This is consistent with one of the primary tenets of controlled attention view-namely, that individuals who are higher in WMC are better able to resist being distracted by information irrelevant to the task at hand (Conway, Cowan, \& Bunting, 2001). Furthermore, this specific pattern of differences, occurring only with irrelevant information, would not be predicted by a general capacity viewpoint of WMC.

\section{GENERAL DISCUSSION}

This set of experiments provides evidence for a potential reinterpretation of the seductive details effect. The results from the first and second experiments have provided evidence that the seduction effect is limited primarily to those individuals who are low in WMC.

From a controlled attention perspective of WMC, the learning results of Experiments 1 and 2 are easily interpretable, since there was a deficit only (1) in individuals who were less able to control their attention and focus on relevant information and (2) when there was irrelevant information that needed to be ignored or otherwise dealt with. These conclusions are further bolstered by the eyetracking results of the second experiment, which demonstrated that the only difference between WMC groups was the amount of irrelevant illustrations viewed, of which high-WMC individuals viewed significantly fewer. This more selective viewing rate of seductive illustrations suggests that those readers higher in WMC were better able to ignore the irrelevant information and could focus, instead, on the text, leading to better comprehension.

On the basis of these overall results, it is our contention that the "capacity" that an individual can hold is not the primary locus of the seduction effect when knowledge is controlled for. Rather, it is the inability of certain individuals to control their attention that leads them to be seduced and, thus, causes them to understand less of the relevant, important information. This finding is consistent with other results in the working memory literature, where the indicator of successful performance is not merely how much one can keep active, but how well one can deal with competition for one's attention (Conway et al., 2001; Conway \& Engle, 1994).

As a final note, one could argue that differences in performance between high- and low-WMC individuals are really due to some kind of general reading ability, an attribute correlated with WMC in the past (Daneman \& Carpenter, 1980). The presence of a higher number of long regressions within the text in Experiment 2 could be seen as evidence for this interpretation, since readers who differed in WMC ability did seem to use different strategies to process the text. However, if reading ability or strategies were a main predictor of performance on comprehension of this text, one would expect differences in performance in the nonillustrated condition between high- and low-WMC individuals. The results of Experiment 1 indicate that this difference was not reliable. Conceding that there are differences in the strategies readers might use to process texts, at least in this case it appears that these differences did not significantly impact understanding of this specific text and that any learning differences must, in fact, have been a result of how different readers dealt with irrelevant illustrations.

This approach has provided insight into a novel consequence of WMC on text comprehension-namely, that one's ability to control attention impacts the ability to deal with irrelevant or distracting information and, as a result, influences the understanding of text. This also has strong implications for the design of future learning environments, since it suggests that the individual characteristics of learners play a crucial role in the development of understanding.

\section{REFERENCES}

Baddeley, A. D, \& Hitch, G. J. (1974). Working memory. In G. H. Bower (Ed.), The psychology of learning and motivation (Vol. 8, pp. 47-89). New York: Academic Press.

BAlluerka, N. (1995). The influence of instructions, outlines, and illustrations on the comprehension and recall of scientific texts. Contemporary Educational Psychology, 20, 369-375.

Bauer, M. I., \& Johnson-Laird, P. N. (1993). How diagrams can improve reasoning. Psychological Science, 4, 372-378.

Benton, S. L., Kraft, R. G., Glover, J. A., \& Plake, B. S. (1984). Cognitive capacity differences among writers. Journal of Educational Psychology, 76, 820-834.

Carpenter, P. A., \& Shah, P. (1998). A model of the perceptual and conceptual processes in graph comprehension. Journal of Experimental Psychology: Applied, 4, 75-100.

Conway, A. R. A., Cowan, N., \& Bunting, M. F. (2001). The cocktail party phenomenon revisited: The importance of working memory capacity. Psychonomic Bulletin \& Review, 8, 331-335.

Conway, A. R. A., \& Engle, R. W. (1994). Working memory and retrieval: A resource-dependent inhibition model. Journal of Experimental Psychology: General, 123, 354-373.

Conway, A. R. A., \& Kane, M. J. (2001). Capacity, control and conflict: An individual differences perspective on attentional capture. In C. L. Folk \& B. S. Gibson (Eds.), Attraction, distraction, and action: Multiple perspectives on attentional capture (pp. 349-372). Amsterdam: Elsevier.

Daneman, M., \& CARPEnter, P. A. (1980). Individual differences in working memory and reading. Journal of Verbal Learning \& Verbal Behavior, 19, 450-466.

Garner, R., Brown, R., Sanders, S., \& Menke, D. J. (1992). "Seductive details" and learning from text. In K. A. Renninger, S. Hidi, \& A. Krapp (Eds.), The role of interest in learning and development (pp. 239-254). Hillsdale, NJ: Erlbaum.

Garner, R., Gillingham, M. G., \& White, C. S. (1989). Effects of "seductive details" on macroprocessing and microprocessing in adults and children. Cognition \& Instruction, 6, 41-57.

Gernsbacher, M. A., VArner, K. R., \& FAust, M. E. (1990). Investigating differences in general comprehension skill. Journal of Experimental Psychology: Learning, Memory, \& Cognition, 16, 430-445.

Goldman, S. R. (1997). Learning from text: Reflections on the past and suggestions for the future. Discourse Processes, 23, 357-398.

Goldman, S. R., Hogaboam, T. W., Bell, L. C., \& Perfetti, C. A. 
(1980). Short-term retention of discourse during reading. Journal of Educational Psychology, 72, 647-655.

HARP, S. F., \& MAYER, R. E. (1997). The role of interest in learning from scientific text and illustrations: On the distinction between emotional interest and cognitive interest. Journal of Educational Psychology, 89, 92-102.

HARP, S. F., \& MAYER, R.E. (1998). How seductive details do their damage: A theory of cognitive interest in science learning. Journal of Educational Psychology, 90, 414-434.

Hegarty, M. (1992). The mechanics of comprehension and comprehension of mechanics. In K. Rayner (Ed.), Eye movements and visual cognition: Scene perception and reading (pp. 428-448). New York: Springer.

Hegarty, M., \& Just, M. A. (1993). Constructing mental models of machines from text and diagrams. Journal of Memory \& Language, 32, 717-742.

Hegarty, M., Kriz, S., \& CATE, C. (2003). The roles of mental animations and external animations in understanding mechanical systems. Cognition \& Instruction, 21, 325-360.

Just, M. A., \& CARPENTER, P. A. (1992). A capacity theory of comprehension: Individual differences in working memory. Psychological Review, 99, 122-149.

KaAkinen, J. K., Hyönä, J., \& Keenan, J. M. (2003). How prior knowledge, WMC, and relevance of information affect eye fixations in expository text. Journal of Experimental Psychology: Learning, Memory, \& Cognition, 29, 447-457.

Kane, M. J., Bleckley, M. K., Conway, A. R. A., \& Engle, R. W. (2001). A controlled-attention view of working-memory capacity. Journal of Experimental Psychology: General, 130, 169-183.

KANE, M. J., \& ENGLE, R. W. (2000). Working-memory capacity, proactive interference, and divided attention: Limits on long-term memory retrieval. Journal of Experimental Psychology: Learning, Memory, \& Cognition, 26, 336-358.

Kane, M. J., Hambrick, D. Z., Tuholski, S. W., Wilhelm, O., Payne, T. W., \& ENGLE, R. W. (2004). The generality of working memory capacity: A latent-variable approach to verbal and visuospatial memory span and reasoning. Journal of Experimental Psychology: General, 133, 189-217.

KINTSCH, W. (1980). Learning from text, levels of comprehension, or: Why anyone would read a story anyway. Poetics, 9, 87-98.

KINTSCH, W. (1988). The use of knowledge in discourse processing: A construction-integration model. Psychological Review, 95, 163-182.

Kintsch, W. (1998). Comprehension: A paradigm for cognition. New York: Cambridge University Press.
KINTSCH, W., \& VAN DiJK, T. A. (1978). Toward a model of text comprehension and production. Psychological Review, 85, 363-394.

LARKIN, J. H., \& Simon, H. A. (1987). Why a diagram is (sometimes) worth ten thousand words. Cognitive Science, 11, 65-100.

MAYER, R. E. (1994). Visual aids to knowledge construction: Building mental representations from pictures and words. In W. Schnotz \& R. W. Kulhavy (Eds.), Comprehension of graphics (pp. 125-138). Amsterdam: North-Holland.

MAYER, R. E. (1999, April). When multimedia works: Designing multimedia for meaningful learning. Paper presented at the annual meeting of the American Educational Research Association, Montreal.

MaYer, R. E., \& Gallini, J. K. (1990). When is an illustration worth ten thousand words? Journal of Educational Psychology, 82, 715-726.

Radvansky, G. A., \& Copeland, D. E. (2004). Working memory span and situation model processing. American Journal of Psychology, 117, 191-213.

Rosen, V. M., \& Engle, R. W. (1997). The role of working memory capacity in retrieval. Journal of Experimental Psychology: General, 126, 211-227.

Schiefele, U. (1999). Interest and learning from text. Scientific Studies of Reading, 3, 257-279.

TURNER, M. L., \& ENGLE, R. W. (1989). Is working memory capacity task dependent? Journal of Memory \& Language, 28, 127-154.

WADE, S. E. (1992). How interest affects learning from text. In K. A. Renninger, S. Hidi, \& A. Krapp (Eds.), The role of interest in learning and development (pp. 255-277). Hillsdale, NJ: Erlbaum.

WADE, S. E., \& ADAMS, B. (1989, March). The effect of interest on sensitivity to importance and learning. Paper presented at the annual meeting of the American Educational Research Association, San Francisco.

Waters, G. S., \& CAPLAN, D. (1996). The capacity theory of sentence comprehension: Critique of Just and Carpenter (1992). Psychological Review, 103, 761-772.

WiLEY, J. (2003). Cognitive and educational implications of visuallyrich media: Images and imagination. In M. Hocks \& M. Kendrick (Eds.), Eloquent images: Writing visually in new media (pp. 201-218). Cambridge, MA: MIT Press.

Wiley, J., MAson, R. A., \& Myers, J. L. (2001). Accessibility of potential referents following categorical anaphors. Journal of Experimental Psychology: Learning, Memory, \& Cognition, 27, 1238-1249.

Wright, P., Milroy, R., \& Lickorish, A. (1999). Static and animated graphics in learning from interactive texts. European Journal of Psychology of Education, 14, 203-224. 


\section{APPENDIX A \\ Image Interest Rating Study}

Method

Subjects. Twenty-seven undergraduates $(N=27)$ from the University of Illinois at Chicago were solicited for participation in this rating study. The subjects were native English speakers and were compensated with course credit in an introductory psychology course at the university.

Materials. All the subjects read the same nonillustrated version of the Web site as that used in the first experiment. After reading the text, the subjects viewed an additional page that contained all 24 images used in the first experiment (both conceptual and seductive). These images were presented in a gallery, and each of the images was individually numbered. Sample images used in this experiment are available in Appendix C. The subjects read the page on IBM-compatible PCs, using Netscape Communicator 4.7, and later completed a rating task that was in paper-and-pencil format.

Procedure. The subjects were first allowed to read the entire expository text. They were instructed to read the text with the goal of developing an argument to answer the question "What causes ice ages?" The subjects were allowed 20 min to complete reading the entire Web page. It was hoped that by allowing the subjects to read the text, in its entirety, they would be better able to make accurate interest ratings of the images, on the basis of how relevant the images were to the topic of ice ages. After the $20 \mathrm{~min}$ had passed, the subjects were then given a rating booklet and were navigated to a new Web page that contained the 24 images.

The subjects were asked two questions in the rating booklet. The first question asked them to place a check mark next to the appropriate item number (all 24 of which were listed in the rating booklet) for any image they thought was conceptually interesting and would further aid in the development of an argument for what causes ice ages. The subjects were also instructed to only check 12 of the 24 images, no more and no less. This requirement forced the subjects to prioritize their perceived conceptual interest for each of the images and, thus, select only the 12 most conceptually interesting images on the basis of what they read. The second question was identical in construction, except that the subjects were asked to place a check (on a separate rating sheet) next to any image number that they found emotionally interesting and irrelevant to the goal of understanding ice ages. They were still allowed to check only 12 images.

In order to compare interest ratings, all 24 images were assigned to one of two a priori groups, on the basis of what condition they were to be used for in the main experiment. The 12 images that were to be used in the conceptual illustration condition were grouped together into the first group (hereafter referred to as the conceptual images group), and those 12 images to be used in the seductive illustration condition were likewise grouped together (the seductive images group). For each subject, total rating scores were computed for each group of pictures by summing the number of checks. Interest ratings for each group of images were then compared, using a within-groups ANOVA. This procedure was done twice, once for each interest question.

\section{Results and Discussion}

For the conceptual ratings, a repeated measures ANOVA indicated that the conceptual images group $(M=$ $9.48, S D=1.50$ ) was rated as significantly higher in conceptual interest than was the seductive images group $(M=2.52, S D=1.50)\left[F(1,26)=144.85, M S_{\mathrm{e}}=4.52, p<.001\right]$. For the emotional interest ratings, the seductive images group $(M=9.30, S D=2.07)$ was rated as significantly higher in emotional interest than was the conceptual images group $(M=2.70, S D=2.07)$, as indicated by a within-groups, repeated measures ANOVA $\left[F(1,26)=68.33, M S_{\mathrm{e}}=8.59, p<.001\right]$.

Overall, these results indicate that the image conditions used in the main experiment are perceived differently from each other. Furthermore, these perceived differences are consistent with the definition of both seductive and conceptual images, as operationalized by prior research (Harp \& Mayer, 1998).

\section{APPENDIX B \\ Sample Nonillustrated Text Used in Main Experiment and Appendix A}

\section{The Great Ice Age}

The Great Ice Age occurred during the Pleistocene era, approximately a million years ago. After a period of warm and equitable climate, mountain glaciers advanced on all continents. The icecaps of Antarctica and Greenland were more extensive and much thicker than they are today, in some places by several thousand feet. So extensive were these glaciers that almost a third of the present land surface of the Earth was covered by ice. Average global temperatures decreased by approximately 8 degrees Celsius. Sea-level was lowered substantially due to the amount of water that was frozen in the great sheets of ice. Ice core analysis also indicates that there were reduced amounts of carbon dioxide present in the atmosphere during this Great Ice Age.

Mountain glaciers are the only remnants of the great glaciers on the mainland of North America. Glaciers from the Great Ice Age are responsible for the formation of numerous U-shaped mountain valleys, lake systems and swamps. These great glaciers also deposited substantial amounts of clay, sand and gravel as they melted and receded. The Great Ice Age is a good example of many ice ages that have occurred throughout the history of the Earth. 
APPENDIX C

Sample Illustrations Used in Experiment 1 and Appendix $A$

Conceptual Images:

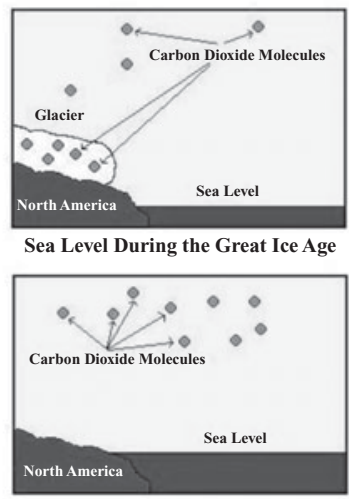

Current Sea Level

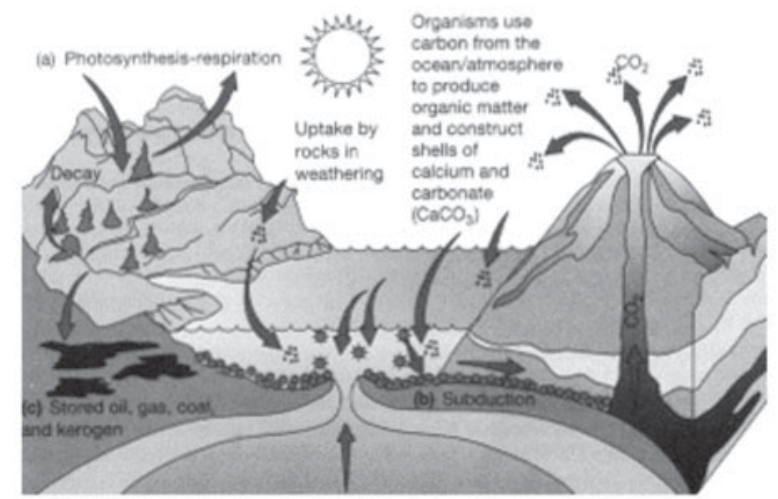

Carbon Dioxide Cycle

Seductive Images:
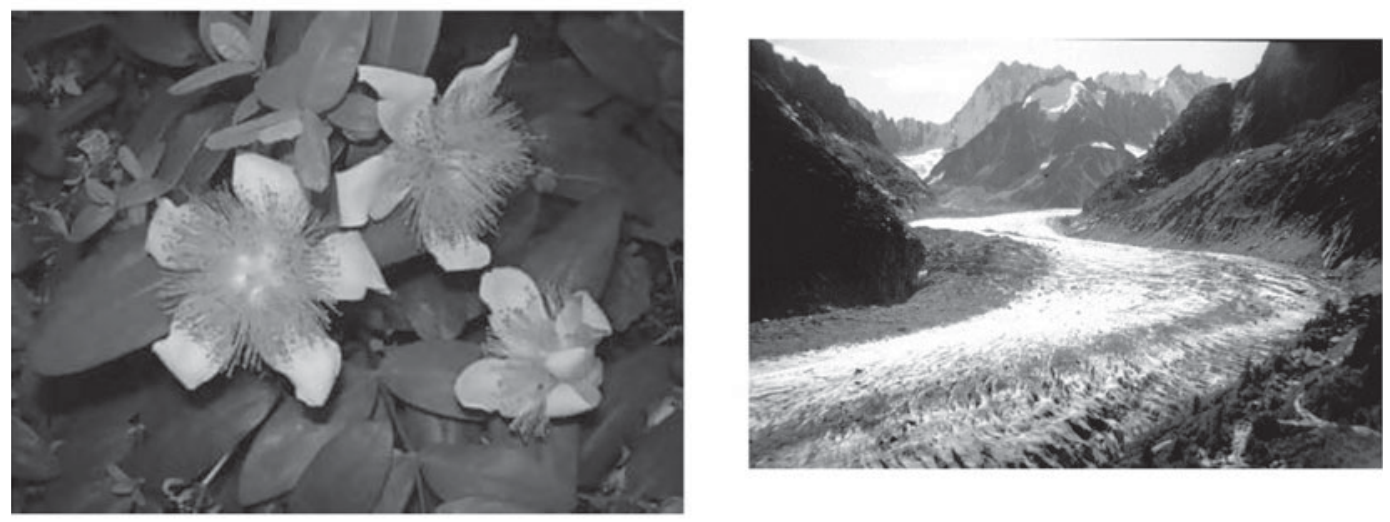

\section{APPENDIX D}

Fifteen Causes of Ice Ages Mentioned in the Text

1. Earth's temperature proceeds in cycles.

2. Less $\mathrm{CO}_{2}$ in the atmosphere leads to cooler temperatures.

3 . Volcanic ash blocks solar radiation.

4. When axis is tilted, sunlight strikes polar regions at very great angles.

5. More snow and ice: $\mathrm{CO}_{2}$ trapped in a frozen state.

6. Less liquid $\mathrm{H}_{2} \mathrm{O}$ equals less opportunity for heat to be distributed around the globe.

7. Sun emits less energy.

8. Changes in ocean currents isolate polar regions.

9. The farther the Earth from the Sun, the less the energy received.

10. Collisions of plates form mountains.

11. Mountains support colder climates.

12. Solar radiation reflected off the surface of the Earth.

13. Amount of solar radiation changes (per region).

14. Collisions of plates form ice/glaciers.

15. Changes in ocean currents cause ice/glaciers to form. 